\title{
Determining Significant Mitigation Measures of Detrimental Variations in Public Building Projects in Tanzania
}

\author{
Yusuph B. Mhando ${ }^{1 *}$, Ramadhan S. Mlinga ${ }^{2}$ and Henry M. Alinaitwe ${ }^{3}$ \\ ${ }^{I}$ Department of Construction Economics and Management, Clo Henry Alinaitwe, Makerere University, $P$. \\ O. Box 7062, Kampala, Uganda, Email: ybmhando@gmail.com (*corresponding author) \\ ${ }^{2}$ Department of Structural and Construction Engineering, University of Dar es Salaam, P. O. Box 35131, \\ Dar-es-Salaam,Tanzania,Email: mlingars@yahoo.co.uk \\ ${ }^{3}$ College of Engineering, Design, Art and Technology (CEDAT), Makerere University, P. O. Box 7062, \\ Kampala, Uganda, Email: alinaitwe_h@cedat.mak.ac.ug
}

\begin{abstract}
Detrimental variations worldwide have led to deleterious effects such as cost overruns, time overruns, compromised quality and abandonment of building projects. The study was about to identify and evaluate potential mitigation measures of detrimental variations in public building projects in Tanzania. This could help in minimizing detrimental variations and consequently safeguarding the anticipated value for money in such projects. Reviewed relevant literature resulted into identification of 17 potential mitigation measures of detrimental variations in public building projects. In total, 183 questionnaire forms were administered to architects, engineers, quantity surveyors and procurement officers for rating. Nevertheless, 143 responses were received constituting $78 \%$ response rate. Moreover, semi-structured interviews were made with 24 selected experienced professionals in public building projects to elicit individual's expert opinion regarding mitigation measures of detrimental variations. Descriptive and inferential statistics such as frequencies, Cronbach's alpha coefficient, coefficient of variations, Principal Component Analysis (PCA) and t-test were used to analyse and syntheses data. Study finding indicates the top five highly ranked potential mitigation measures of detrimental variations as joint efforts by project parties to control variation orders, clear project specifications, comprehensive site investigations, use of project scheduling techniques and use of knowledge base of previous similar projects. The agreement among respondents in rating and ranking mitigation factors was found to be significant. Overall, respondents tended to agree that all rated and ranked 17 mitigation measures could be practical to minimise detrimental variations in construction projects since their expected values of discrete random variables were greater than 3. Results from this study should help professionals, academicians, researchers and policy makers to reduce detrimental variations and subsequently improve performance of construction projects.
\end{abstract}

Keywords: Detrimental, Mitigation measures, Public building projects, Tanzania, Variations

\section{Introduction}

Detrimental variations on construction projects continue to be a chronic problem worldwide and the situation is getting worse. Many public building projects, particularly in developing countries have been subjected to detrimental variations often leading to cost overruns, time overruns, project abandonment, rework, disruption and conflicts. Consequently, these have led to non-fulfillment of project objectives. Tanzania being a developing country has problems related to detrimental effects of variations in developing its public building projects [1]. In the context of Tanzania construction sector, it is observed that, instead of a project taking two years it takes more than three years with its cost doubling [2]. This unfavourable circumstance resulting from the adverse impacts of variations tends to raise concern on infrastructure facilities developed through meager public resources that fail to provide value for money. It is argued that, to achieve project objectives one would expect the project to be completed within the initially anticipated cost, time and quality, but reality takes the opposite direction [3]. As a result of detrimental variations, many cases of poor quality, late completion and cost overruns are being reported in many construction projects in Tanzania and some of these projects have not been successfully implemented as expected [4]. Apparently, to date, detrimental variations on the performance of construction projects were observed by many researchers. However, most of these researchers were too general with little contemplation on identifying the potential mitigation measures of detrimental variations. As a result, these researchers have inadequately documented mitigation measures to curb detrimental variations in public building projects. Researchers such as Subramani et al. [5] and Ubani et al. [6] managed to outline few mitigation measures of detrimental variations in the construction industries of India and Nigeria respectively which inevitably fuel the need to look comparatively the experience in other construction industries. Moreover, researchers identified this area of study as deserving attention since none of the studies highlighted addressed the mitigating procedures of detrimental variations on the performance of public building projects in Tanzania. 
Arain and Pheng [7] affirm that a detrimental variation is one that negatively impacts the project performance. In fact, detrimental variations pessimistically impact various aspects of the project performance such as cost, schedule and quality. This implies that, detrimental variations could inflict substantial adjustment to the contract sum and duration of the project. This scenario compels the need to mitigate detrimental variations during construction process of building projects, as the major instances of project cost and time overruns take place during construction phase. Memon et al. [8] argue that it is very important to control variations in construction projects. Impliedly, to uncover variations mitigation measures would be significant for various practical and theoretical purposes, especially for improving performance in construction projects.

Specifically, this study was carried out to identify, evaluate and document the potential mitigation measures of detrimental variations in public building projects in Tanzania. Arain [9] stipulate that mitigation measures provide practical informed decisions to professionals for effective strategic management of variations. The study was achieved through a detailed literature review coupled with questionnaire and interview surveys employed to obtain views from professionals with regard to mitigating factors of detrimental variations in public building projects. Questionnaire and interview surveys have been used successfully in many studies such as those by Moghaddam [10] and Priyantha et al. [11] in generalizing results into other contexts. By the help of Statistical Package for Social Sciences (SPSS) software, data from questionnaire were analysed and synthesised. Consequently, potential mitigating measures of detrimental variations were identified, evaluated and ranked according to their importance and occurrence. This study seeks to contribute towards finding solutions for minimising detrimental variations in public building projects. Findings from this study should benefit construction stakeholders such as policy makers, construction practitioners and academicians to improve construction performance. The rest of the article is organised as follows: first, the literature on detrimental variations, their effects and mitigating measures were reviewed. This is followed by a description of research methods and data analysis techniques used for the study. Results of the study are then discussed. The paper concludes with discussion of theoretical, practical and managerial implications and directions for future research.

\subsection{Detrimental Variations with their Adverse Effects}

\section{Literature Review}

Variation is defined as the change, modification, alteration, revision or amendment to the original intent of the contract and /or its works [12]. It may involve the alteration of kind or standard of any materials to be used in the works [13]. Moreover, it is an area of research in the construction industry that still needs to be researched, as it has received limited attention. Hao et al. [14] affirm that there is a very limited research work addressing the change management issues specifically within the construction project management context. Arain and Pheng [7] insist that a detrimental variation is one that negatively impacts the project performance. In fact, detrimental variations pessimistically impact various aspects of the project performance such as cost, schedule and quality. To date, detrimental variations on the performance of construction projects were observed by many researchers. However, most of these researchers were too general with little contemplation on their potential mitigation measures. Researchers such as Subramani et al. [5] and Ubani et al. [6] managed to outline few mitigation measures of detrimental variations in the construction industries of India and Nigeria respectively which inevitably fuel the need to look comparatively the experience in other construction industries. Babatunde [15] and Ismail et al. [16] point out that variation with their attached adverse effects in construction projects are a global phenomenon. Variations are caused by various factors and often cause disputes and dissatisfactions among the parties involved in construction projects [8]. It is argued that construction process is subject to many variables and unpredictable factors resulting from many sources [17]. Variations are one of these variables and unpredictable factors related to the project participants with the consequence of changes in the scope of work. Most building projects are liable to variations that might be caused by change of mind of the clients, consultants or any unforeseen scope of the project raised by one of the project participants. These changes can lead to deviations from the sum stipulated in the contract [18]. Evidently, most construction projects especially in developing countries, usually suffer from cost and time overruns due to variations in project plans with the consequence of stagnated economic development $[16,6]$. This situation compels the need to mitigate detrimental variations during construction process of building projects, as the major instances of project cost and time overruns take place during construction phase.

\subsection{Mitigation Measures}

Mitigation is the implementation of measures designed to minimize, avoid, or remedy adverse impacts of a phenomenon such as detrimental variations in construction projects. Memon et al. [8] argue that it is very important to control variations in construction projects. Impliedly, to uncover variations mitigation measures would be significant for various practical and theoretical purposes, especially for improving performance in 
construction projects. Mitigation measures provide practical informed decisions to professionals for effective strategic management of variations [9].

Hao et al. [14] proposed clear design specifications before bidding and curbing corruption in procurement process as the potential mitigation measures of detrimental variations in construction projects in Canada. As a former Chief Executive Officer (CEO) at the Public Procurement Regulatory Authority (PPRA), Mlinga [4] further argues that the procurement process rules must be clear, open, well understood and applied equally to all parties to the process. The application of the highest ethical standards will help ensure the best achievable procurement outcomes with constrained corruption practices in the tendering process.

Memon et al. [8] found that client involvement during construction phase and prompt written approval procedures as potential mitigation measures in construction projects of Malaysia. Memon et al. [8] recommend that client and other parties should be involved during the construction phase to assist in clarifying the project objectives and in identifying the noncompliance with the project requirements. It is argued that prompt decision making goes hand in hand with clear understanding of the project objectives. Moreover, prompt approval procedures would assist in reducing the adverse effects of variations in construction projects.

Ubani et al. [6] identified engagement of project manager to manage the project, clarity of variation order procedures, control for variation orders to arise through contractual clauses and effective use of scheduling techniques as potential mitigation measures of detrimental variations in the Nigerian construction industry. In his research, Moghaddam [10] found that variation logic, variation justification and valuation of indirect effects of variations as significant mitigation measures in the Iranian construction industry. The logic and justification technique behind the proposed variations assists the professionals to promote advantageous variations and eliminate detrimental variations in construction projects. Furthermore, indirect effects of variations result in severe impacts on project budget or schedule [10]. Consequently, it is quite imperative for professionals to acknowledge these indirect effects of variations and establish an appropriate method to evaluate and manage them professionally and effectively.

Other potential mitigation measures of detrimental variations were also identified in other countries such as comprehensive site investigations Subramani et al. [5] in India; teamwork spirit among project parties Aiyetan and Smallwood [19] in south Africa; proper use of collected and organised project data compiled by client Rajeev and Kothai [20] in India; use of knowledge base of previous similar projects Emuze and Smallwood [21] in south Africa; proper utilization of work break down structures (WBS) Tadayon et al. [22] in Iran and; restricted pre-qualification system for awarding projects Ammar et al. [23] in Egypt. Impliedly, a restricted pre-qualification system for awarding projects would help to restrict incapable contractors to bid. However, this allows capable contractors only to have chance to bid the project. To allow incapable contractors to bid due to lack of restricted pre-qualification system for awarding projects may eventually lead to numerous problems including variations at the construction stage of the project. This means that the more the skilled and competent consultant and contractor have identified at the tender stage, the less the detrimental variations to be experienced during the construction process. Table 1 shows a summary of the identified potential mitigation measures of detrimental variations in building projects. The next section discusses research methods and data analysis techniques used for the study.

Table1: Mitigation measures of detrimental variations

\begin{tabular}{|l|l|}
\hline Mitigation Measures & References \\
\hline Effort by client, consultant and contractor to control variation orders & {$[8],[7]$} \\
\hline Comprehensive site investigations & {$[5]$} \\
\hline Clear design specifications & {$[8],[14]$} \\
\hline Engagement of project manager to manage the project & {$[24]$} \\
\hline Teamwork spirit & {$[19]$} \\
\hline Proper use of collected and organised project data compiled by client & {$[20]$} \\
\hline Variation logic and justification & {$[10]$} \\
\hline Use of knowledge base of previous similar projects & {$[21]$} \\
\hline Clients involvement during construction phase & {$[8]$} \\
\hline Prompt written approval procedures & {$[8],[7]$} \\
\hline Use of project scheduling techniques & {$[6]$} \\
\hline Clarity of variation order procedures & {$[6]$} \\
\hline Proper utilization of work break down structures (WBS) & {$[22]$} \\
\hline Initiatives aimed at curbing corruption & {$[25],[14],[4]$} \\
\hline Valuation of indirect effects & {$[10]$} \\
\hline Potential control for variation orders to arise through contractual clauses & {$[5],[6]$} \\
\hline Restricted pre-qualification system for awarding projects & {$[11],[23]$} \\
\hline
\end{tabular}




\subsection{Research Design}

\section{Research Methodology}

There are five research styles: experiment, survey, action research, ethnographic research and case study [26]. Ying [27] considers that there are five common research strategies in the social sciences: surveys, experiments, histories, epidemiologic research and case studies. However, the adoption of the appropriate research design depends on the logic that links the data collected and data analysis to yield results that give answers to the main research questions being investigated. Fellows and Liu [28] stipulate that surveys operate on the basis of statistical sampling; only extremely rarely are full population surveys possible, practical or desirable. Fellows and Liu [28] further clarify that, commonly, samples are surveyed through questionnaires or interviews. Consequently, questionnaire survey and interview survey approaches were adopted for the study. The adoption of quantitative and qualitative approaches could help to maximize the strengths and minimize the limitations of each technique [29].

\subsection{Study Population}

Population of the study comprised of engineers registered by Engineers Registration Board (ERB), architects and quantity surveyors registered by Architects and Quantity Surveyors Registration Board (AQRB) and, procurement and supplies officers registered by Procurement and Supplies Professionals and Technician Board (PSPTB) in Tanzania.

\subsection{Questionnaire Design}

Questionnaire form was divided into two main sections. On one hand, the respondent was asked to fill in the space provided with the appropriate respondent's general information. On the other hand, the respondent was asked to rate causes of variation variables using five-point Likert scale viz-a-viz: strongly disagree $=1$; disagree $=2$; neutral $=3$; agree $=4$ and strongly agree $=5$. Likert Scale Rating System (LSRS) has been used successfully by many researchers such as Memon et al. [8] and Subramani et al. [5] in their studies.

\subsection{Pilot Study}

Pilot study was conducted to find out if the questionnaire was able to measure what was supposed to be measured; the wording was clear; if all questions were interpreted in the same way by respondents; what responses were provided; and if there was any research bias. It is argued that, to ensure the effectiveness of a questionnaire, a pre-test should be carried out by piloting the questionnaire with a small representative sample [29]. Furthermore, a pilot study helps to refine data collection plans with respect to both the content of the data and the procedure to be followed [27]. Therefore, a judgment sample of 18 respondents with good spread of respondent characteristics was chosen for the preliminary testing of the questionnaire. The questionnaires were administered to professionals (architects, engineers, quantity surveyors and procurement officers) contacted in person. Nevertheless, only 9 respondents were able to return the filled questionnaire forms. Based on their feedback, corrections were made to improve the format, layout, questions and the overall content of the questionnaire. Through this process, the questionnaire was validated and provided the authors with improvement opportunity prior to main survey.

\subsection{Sampling Technique}

Given the wide distribution of public building projects and their heterogeneous nature around Tanzania, the purposive sampling method was used in this study. Purposive sampling involves searching for cases or individuals who meet a certain criterion [30]. Also, researchers' sample must be tied to their objectives [30]. It is argued that, purposive sampling is a technique widely used in research for the identification and selection of information-rich cases for the most effective use of limited resources [31]. Moreover, purposive sampling technique, also called judgment sampling, is a deliberate choice of an informant due to the qualities that the informant possesses [32].

\subsection{Sample Size}

A total of 183 questionnaires were purposeful distributed to 36 architects, 42 quantity surveyors, 90 engineers and 15 procurement officers contacted in person to get individual perceptions. Telephone call and short message system (SMS) reminders were used to remind the respondents to fill the questionnaire form. Table 2 shows that 143 valid responses were received, constituting a response rate of $78 \%$, which is considered adequate for data analysis. Relatively, semi-structured interviews with open-ended questions were made with 24 participants selected from 143 respondents participated in the questionnaire survey. The interview was about to probe and elicit individual's expert perception regarding mitigation measures of detrimental variations. Moreover, all ethical issues with regard to interviewing were observed during and after the interview process. Participants chosen to be interviewed were homogeneous, sharing same characteristics, with almost similar 
experiences and all were involved in public building projects. Specifically, the interviews were made with contacted 3 architects, 11 engineers and 10 quantity surveyors.

Table 2: Demographic of survey participants

\begin{tabular}{|c|c|c|c|c|}
\hline $\begin{array}{c}\text { Registration } \\
\text { Board }\end{array}$ & $\begin{array}{c}\text { Participants' } \\
\text { Category }\end{array}$ & $\begin{array}{c}\text { Questionnaires sent } \\
\text { (sample size) }\end{array}$ & Response & $\begin{array}{c}\text { Response } \\
\text { Rate }(\%)\end{array}$ \\
\hline AQRB & Architects & 36 & 12 & 33.3 \\
\hline ERB & Engineers & 90 & 84 & 93.3 \\
\hline AQRB & Quantity surveyors & 42 & 35 & 83.3 \\
\hline PSPTB & Procurement officers & 15 & 12 & 80.0 \\
\hline & Total & 183 & 143 & 78.0 \\
\hline
\end{tabular}

\subsection{Data Analysis}

Data analysis was done with the help of the Statistical Package for Social Sciences (SPSS) version 17. The data collected from the questionnaire survey were coded and entered into the SPSS computer software program that analyzed statistically all the required statistics such as frequencies, Cronbach's alpha reliability test, mean, standard deviations and t-test to draw inferences. Statistics such as variances and coefficient of variations of the participants' evaluations of the mitigation factors of detrimental variations in building projects were then calculated as shown in the equations 1,2 and 3 respectively:

$$
\begin{aligned}
& E(x)=\sum_{i=1}^{n} x_{i} p\left(x_{i}\right) \\
& V(x)=E(X-\mu)^{2} \\
& \operatorname{COV}(x)=\frac{\sqrt{V(x)}}{E(x)}
\end{aligned}
$$

Where $\mathrm{E}(\mathrm{x})$ is the expected value of a discrete random variable $\mathrm{X}, \mathrm{x}$ are the values of the random variable for which $\mathrm{p}(\mathrm{x})>0, \mathrm{p}(\mathrm{x})$ is the probability distribution, $\mu$ is the mean, $\mathrm{V}(\mathrm{x})$ is the variance of random variable $\mathrm{X}$, and $\operatorname{COV}(\mathrm{x})$ is the coefficient of variation. Based on the evaluation of the mitigation factors in each country of Tanzania and Uganda, the factors were ranked by their respective coefficient of variations. Ranking by $\mathrm{COV}$ has been employed before and is considered reliable because it considers both $\mathrm{E}(\mathrm{x})$ and $\mathrm{V}(\mathrm{x})$ values. Many researchers such Alinaitwe and Ayesiga [33] and Mahamid and Dmaidi [34] have successfully used COV for ranking in their studies.

\subsection{Cronbach's Alpha Reliability Testing}

\section{Results and Discussion}

The reliability test was conducted using SPSS version 17 to determine whether the questionnaire was capable of yielding similar scores if the respondents used it twice. Reynolds and Santos as in Alinaitwe et al. [35] point out that an alpha greater than 0.7 implies the instrument is acceptable. The determined Cronbach's alpha $(\alpha)$ value for the study was 0.813 , which indicates that strong agreement existed between construction industry practitioners in ranking of the factors, and accordingly that the survey instrument used was a reliable tool. According to Zadeh et al. [36] Cronbach's alpha coefficient is usually computed from the following formula:

$$
\text { Alpha }=\frac{N C}{V+(N-1) * C}
$$

(Equation 4)

Where $\mathrm{N}=$ the number of items, $\mathrm{V}=$ the average variance and $\mathrm{C}=$ the average inter-item covariance.

\subsection{Demographic Analysis of the Survey Participants}

Table 2 indicates that $79(55.2 \%)$ respondents were from government, $39(27.3 \%)$ were from consultants and $25(17.5 \%)$ were from contractors. These statistics affirm that the majority of participants were from government. Furthermore, $118(83 \%)$ respondents were male and $25(17 \%)$ were female which implies that male participants were the majority. In the case of education level, about $110(77 \%)$ respondents were undergraduates possessing first degree, $32(22 \%)$ were master degree holders and 1(1\%) respondent was a doctoral degree $(\mathrm{PhD})$ holder. Relatively, $43(30 \%)$ respondents have work experience ranging between 0-5 years, 37 (26\%) have work experience between 6-10 years, 19 (13\%) between 11-15 years, 17 (12\%) from 1620 years, $9(6 \%)$ have work experience between 21-25 years and, $18(13 \%)$ have work experience more than 25 
years. The determined average of 15 years of professional work experience of respondents was considered suitable and that they have acquired adequate experiences from the construction industry such that, based on this argument, the responses given by those professionals are reliable and trustworthy.

Table 3: Demographics of questionnaire respondents

\begin{tabular}{|c|c|c|c|}
\hline Characteristics & Frequency & Percentage & Cumulative Percentage \\
\hline \multicolumn{4}{|l|}{ Type of Organisation } \\
\hline Client & 79 & 55 & 55 \\
\hline Consultant & 39 & 27 & 87 \\
\hline Contractor & 25 & 18 & 100 \\
\hline Total & 143 & 100 & \\
\hline \multicolumn{4}{|l|}{ Sex } \\
\hline Male & 118 & 83 & 83 \\
\hline Female & 25 & 17 & 100 \\
\hline Total & 143 & 100 & \\
\hline \multicolumn{4}{|l|}{ Education Level } \\
\hline Undergraduate Degree & 110 & 77 & 77 \\
\hline Master Degree & 32 & 22 & 99 \\
\hline $\mathrm{PhD}$ & 1 & 1 & 100 \\
\hline Total & 143 & 100 & \\
\hline \multicolumn{4}{|l|}{ Work Experience } \\
\hline $0-5$ years & 43 & 30 & 30 \\
\hline $6-10$ years & 37 & 26 & 56 \\
\hline $11-15$ years & 19 & 13 & 69 \\
\hline $16-20$ years & 17 & 12 & 81 \\
\hline $21-25$ years & 9 & 6 & 87 \\
\hline More than 25 years & 18 & 13 & 100 \\
\hline Total & 143 & 100 & \\
\hline
\end{tabular}

\subsection{Interview Results}

Result of interviews demonstrates that public building projects have suffered detrimental variations, particularly related to internal factors. Interview participants expressed their expert based diverse perceptions with regard to mitigation measures of detrimental variations in public building projects. Results suggest the most important mitigation measures of detrimental variations as involvement of all project stakeholders at all stages of the project to help clarify project objective; employment of skilled, experienced and competent professionals to undertake the project; precise estimates to avoid changes at construction stage; avoidance of design discrepancies and provision of sufficient time for the design. Other mitigation measures cited by respondents which were also identified in other countries include engagement of independent and skilled project manager to manage the project Enshasi et al. [24] in Gaza Strip, Palestine; use of knowledge base of previous similar projects Emuze and Smallwood [21] in South Africa and; team work spirit at all stages of the project development Aiyetan and Smallwood [19] in South Africa.

Likewise, participants outlined significant mitigation measures as adoption of new technology; thorough compilation of data required for the project; ensuring accurately and timely approval procedures; availability of materials and equipment should be considered before the design; provision of enough budget for the project and avoidance of delay in payment; client's project objectives should be clearly known at the early stage of the project; availability of adequate design and working drawings before tendering process; ensure proper coordination and communication among project parties. Interestingly, respondents were motivated such that they were able to identify more mitigation measures which were also observed in other construction industries. These mitigation measures include carrying out thorough site feasibility study before commencement of the design Subramani et al. [5] in India; making use of proper scheduling techniques Ubani et al. [6] in Nigeria and ensure variation logic and justification Moghaddam [10] in Iran.

Furthermore, respondents cited potential mitigation measures as transparency in budgeting and accounting system; early detection of possible risks and handling; observant of project's legislative requirements in all project stages; controlling variations at the start of the project and subsequent stages and; proper project scoping and utilization of early warning clauses by contractor to enable necessary adjustments. Similarly, participants were able to outline more potential mitigation measures which were also observed in other parts of the world such as clear and concise design specifications Memon et al. [8, 14] in Malaysia and Canada respectively and; Utilization of work breakdown structure (WBS) techniques Tadayon et al. [22] in the Iranian construction industry. Consequently, the outlined mitigation measures from interviews were used for endorsement of findings from the questionnaire survey. 


\subsection{Mitigation Measures from Questionnaires}

Result in Table 4 shows that effort by client, consultant and contractor to control variation orders was ranked 1st as the most effective mitigation measure of variations. This claim is supported by Arain and Pheng [7] who suggest that coordination of project parties is important in construction projects. This assists the parties in identifying the potential variations during the early stage of the construction project. Relatively, clear project specifications was ranked 2nd. Arguably, changes in specifications often result in variations to the project, leading to delay and increased overall project cost [8]. Ideally, carefully provision of detailed specification documents before bidding is paramount [14]. Comprehensive site investigation was ranked 3rd. Subramani et al. [5] affirm that poor field investigation and inadequate feasibility analysis has led to variations resulting into cost overruns. Evidently, although ranked 16th restricted pre-qualification system for awarding projects was agreed by respondents to be the mitigation measure of variations in building projects. Impliedly, a restricted prequalification system for awarding projects would help to restrict incapable contractors to bid. This claim is supported by Ammar et al. [23] who point out that owner should adopt a pre-qualification system and make sure that contractors are not selected based on the lowest bid only.

Other ranked factors which were also identified in other countries include use of knowledge base of previous similar projects Emuze and Smallwood [21] in South Africa; engagement of project manager to manage the project Enshasi et al. [24] in Gaza Strip, Palestine; team work spirit Aiyetan and Smallwood [19] in South Africa; comprehensive site investigations Subramani et al. [5] in India; use of project scheduling techniques Ubani et al. [6] in Nigeria; variation logic and justification Moghaddam [10] in Iran; clear design specifications Memon et al. [8] and Hao et al. [14] in Malaysia and Canada respectively and; proper utilization of work breakdown structure (WBS) techniques Tadayon et al. [22] in the Iranian construction industry. Overall, potential control for variation orders to arise through contractual clauses was the least ranked. However, respondents tended to agree that all 17 mitigation factors can be useful measures to reduce variations in construction projects since their $\mathrm{E}(\mathrm{x})$ values were greater than 3 .

Table 4: Ranking mitigation measures of detrimental variations

\begin{tabular}{|c|c|c|c|c|}
\hline \multirow[b]{2}{*}{ Mitigation Variables } & \multicolumn{4}{|c|}{$\mathbf{N}=143$} \\
\hline & $\mathbf{E}(\mathbf{x})$ & $\sqrt{\mathbf{V}(\mathbf{x})}$ & $\mathrm{COV}$ & Rank \\
\hline Effort by client, consultant and contractor to control variation orders & 4.3986 & 0.68320 & 0.1553 & 1 \\
\hline Clear design specifications & 4.3147 & 0.72597 & 0.1682 & 2 \\
\hline Comprehensive site investigations & 4.3357 & 0.79562 & 0.1835 & 3 \\
\hline Use of project scheduling techniques & 3.9930 & 0.78270 & 0.1960 & 4 \\
\hline Use of knowledge base of previous similar projects & 4.0070 & 0.80050 & 0.1998 & 5 \\
\hline Variation logic and justification & 4.0070 & 0.82647 & 0.2062 & 6 \\
\hline Teamwork spirit & 4.1678 & 0.87199 & 0.2092 & 7 \\
\hline Engagement of project manager to manage the project & 4.1678 & 0.90372 & 0.2168 & 8 \\
\hline Proper use of collected and organised project data compiled by client & 4.0769 & 0.88872 & 0.2179 & 9 \\
\hline Clarity of variation order procedures & 3.9930 & 0.87610 & 0.2194 & 10 \\
\hline Proper utilization of work break down structures (WBS) & 3.9510 & 0.89858 & 0.2274 & 11 \\
\hline Valuation of indirect effects & 3.7203 & 0.89132 & 0.2396 & 12 \\
\hline Prompt written approval procedures & 4.0000 & 0.99293 & 0.2482 & 13 \\
\hline Clients involvement during construction phase & 4.0000 & 1.00000 & 0.2500 & 14 \\
\hline Initiatives aimed at curbing corruption & 3.7343 & 1.09384 & 0.2929 & 15 \\
\hline Restricted pre-qualification system for awarding projects & 3.5245 & 1.09950 & 0.3120 & 16 \\
\hline Potential control for variation orders to arise through contractual clauses & 3.5524 & 1.12387 & 0.3164 & 17 \\
\hline
\end{tabular}

\subsection{Principal Component Analysis (PCA)}

The Principal Component Analysis (PCA) was carried out by using Varimax Orthogonal Rotation Criteria (VORC) to explore and understand the underlying relationships within the 17 mitigation variables used in this study. PCA has been used successfully by many researchers such as Alinaitwe et al. [35] and Aiyewalehinmi [37] in their studies. It is argued that a Kaiser-Meyer-Olkin (KMO) value close to 1 indicates that the patterns of correlations are relatively compact and so factor analysis should yield distinct and reliable factors. It also specify that values between 0.00 and 0.49 don't factor, values between 0.5 and 0.7 are mediocre, values between 0.7 and 0.8 are good, values between 0.8 and 0.9 are great and values above 0.9 are superb. From Table 5, the determined KMO value was 0.839, which falls into the range of being great. Further, the determined approximate Chi-square in the Bartlett's test of sphericity was 870.103 and the significance was 0.000 . These values provide confidence that the conducted factor analysis was appropriate and the variables were correlated highly enough to provide a reasonable basis for factor analysis. Table 6 indicates the extracted five components whose Eugenie values were over 1.000 . They accounted for $64.375 \%$ of the common variance shared by the 17 variables which is above the required minimum of $60 \%$ as advocated by Hair et al. in Chan and Hung [38]. The extracted five components from factor analysis were outlined as methodical involvement of all key stakeholders of the project to help in clarifying the project objectives at all stages of implementation (F1), 
adherence to contractual arrangement with regard to variation orders (F2), adherence to ethical procedures of procurement and transparency in budgeting and accounting system (F3), thorough feasibility study and compilation of data needed for the project (F4), precise contract management would help to control detrimental variations in public building projects (F5). Apparently, these issues were of great concern to participants in evaluating the potential mitigation measures of detrimental variations in building projects.

Table 5: Bartlett's test and KMO for the factors

\begin{tabular}{|l|l|l|}
\hline \multicolumn{2}{|c|}{ KMO and Bartlett's Test } \\
\hline Kaiser-Meyer-Olkin Measure of Sampling Adequacy. & 0.839 \\
\hline Bartlett's Test of Sphericity & Approx. Chi-Square & 870.103 \\
\cline { 2 - 3 } & df & 136 \\
\cline { 2 - 3 } & Sig. & 0.000 \\
\hline
\end{tabular}

Table 6: Results of factor analysis showing the factor loadings

\begin{tabular}{|c|c|c|c|c|c|}
\hline \multirow[b]{2}{*}{ Mitigation Measures of Detrimental Variations } & \multicolumn{5}{|c|}{ Component } \\
\hline & F1 & F2 & F3 & F4 & F5 \\
\hline Clients involvement during construction phase & & & & .685 & \\
\hline Prompt written approval procedures & & & & .700 & \\
\hline Engagement of project manager to manage the project & & & & .732 & \\
\hline Variation logic and justification & .766 & & & & \\
\hline Use of project scheduling techniques & .742 & & & & \\
\hline Clarity of variation order procedures & .787 & & & & \\
\hline Clear project specifications & & & & & \\
\hline Restricted pre-qualification system for awarding projects & & .779 & & & \\
\hline Initiatives aimed at curbing corruption & & .701 & & & \\
\hline Teamwork spirit & & & & & \\
\hline Proper utilization of work break down structures (WBS) & & .810 & & & \\
\hline Effort by client, consultant and contractor to control variation orders & & & .608 & & \\
\hline Comprehensive site investigations & & & .636 & & \\
\hline Proper use of collected and organised project data compiled by client & & & .658 & & \\
\hline Use of knowledge base of previous similar projects & & & .681 & & \\
\hline Potential control for variation orders to arise through contractual clauses & & & & & .786 \\
\hline Valuation of indirect effects & & & & & \\
\hline
\end{tabular}

Table 7: One sample t-test for mitigation measures of variations

\begin{tabular}{|c|c|c|c|c|c|}
\hline \multirow{2}{*}{ Mitigation Variables } & \multicolumn{3}{|c|}{ Test value $=3$} & \multicolumn{2}{|c|}{ df $=142$} \\
\hline & $\mathbf{t}$ & $\begin{array}{c}\text { Sig. } \\
\text { (2-tailed) }\end{array}$ & $\begin{array}{c}\text { Mean } \\
\text { Difference }\end{array}$ & \multicolumn{2}{|c|}{$\begin{array}{l}95 \% \text { Confidence } \\
\text { Interval of the } \\
\text { Difference }\end{array}$} \\
\hline Effort by client, consultant and contractor to control variation orders & 24.480 & 0.000 & 1.39860 & 1.2857 & 1.5115 \\
\hline Clear design specifications & 21.656 & 0.000 & 1.31469 & 1.1947 & 1.4347 \\
\hline Comprehensive site investigations & 20.075 & 0.000 & 1.33566 & 1.2041 & 1.4672 \\
\hline Use of knowledge base of previous similar projects & 15.043 & 0.000 & 1.00699 & 0.8747 & 1.1393 \\
\hline Variation logic and justification & 14.570 & 0.000 & 1.00699 & 0.8704 & 1.1436 \\
\hline Teamwork spirit & 16.015 & 0.000 & 1.16783 & 1.0237 & 1.3120 \\
\hline Engagement of project manager to manage the project & 15.453 & 0.000 & 1.16783 & 1.0184 & 1.3172 \\
\hline Proper use of collected and organised project data compiled by client & 14.491 & 0.000 & 1.07692 & 0.9300 & 1.2238 \\
\hline Clarity of variation order procedures & 13.554 & 0.000 & 0.99301 & 0.8482 & 1.1378 \\
\hline Clients involvement during construction phase & 11.958 & 0.000 & 1.00000 & 0.8347 & 1.1653 \\
\hline Initiatives aimed at curbing corruption & 8.027 & 0.000 & 0.73427 & 0.5534 & 0.9151 \\
\hline Restricted pre-qualification system for awarding projects & 5.704 & 0.000 & 0.52448 & 0.3427 & 0.7062 \\
\hline $\begin{array}{l}\text { Potential control for variation orders to arise through contractual } \\
\text { clauses }\end{array}$ & 5.878 & 0.000 & 0.55245 & 0.3667 & 0.7382 \\
\hline
\end{tabular}

\subsection{One-Sample t-test Analysis}

One-sample t-test analysis was employed to test for significance in ranking the factors of variations. The test value was set as 3 because the rating scale ranges from 1 to 5 with 3 being a neutral position. The 2tailed test for level of significance in Table 7 shows that all values are less than 0.05 meaning that, the ratings were significant. Likewise, the $t$ values demonstrate that the rating of the factors was significant since they are above or below zero. Relatively, the $95 \%$ interval of difference $(\rho=0.05)$ shows that all rated factors have both 
the upper and lower limits above zero meaning that they are practically significant. Impliedly, the difference in means is statistically significant at the 0.05 confidence level. Therefore, it can be inferred that the ratings of mitigation variables were significant.

\subsection{Conclusions}

\section{Conclusion And Recommendations}

The study findings demonstrated that public building projects suffered because of the detrimental variations. Based on the research objectives, potential mitigation measures of detrimental variations in public building projects were identified, evaluated, ranked and have been concluded as follows:

\subsubsection{Mitigation Measures of Detrimental Variations}

Factors such as Effort by client, consultant and contractor to control variation orders; Clear design specifications; Comprehensive site investigations; Use of project scheduling techniques and; Use of knowledge base of previous similar projects appear to be the most five important mitigation measures for detrimental variations in public building projects. Certainly, respondents tended to agree that all 17 mitigation factors can be useful measures to reduce variations in construction projects since their $\mathrm{E}(\mathrm{x})$ values were greater than 3 .

\subsubsection{Principal Component Analysis (PCA)}

The Principal Component Analysis (PCA) was carried out by using Varimax Orthogonal Rotation Criteria (VORC) to explore and understand the underlying relationships within the 17 mitigation variables used in this study. Consequently, the extracted five components were identified as factors F1, F2, F3, F4 and F5. Apparently, these factors were of great concern to participants in evaluating the potential mitigation measures of detrimental variations in building projects.

\subsubsection{T-test Analysis}

The t-test analysis was used to determine the significance of ratings. In fact, from the test results, it can be inferred that, the ratings of the mitigation factors of detrimental variation variables were significant. This implies that the agreement among respondents in rating and ranking mitigation factors was significant.

\subsubsection{Practical and Managerial Implications}

The study findings could provide useful insights in engendering managerial efficiencies and effectiveness towards successfully improvement of construction performance. Findings of this study should inform the professionals, policy makers, academicians and researchers to improve performance of building projects. Likewise, findings of this study could be used as input for future studies.

\subsection{Recommendations}

Based on the study findings, the researchers recommend the following: thorough involvement of all key stakeholders of the project to help in clarifying the project objectives at all stages of implementation, adherence to contractual arrangement with regard to variation orders, adherence to ethical procedures of procurement and transparency in budgeting and accounting system, methodical feasibility study and compilation of data needed for the project and; contract management practice would be beneficial and effective ways of mitigating detrimental variations in public building projects.

\section{Contributions}

Overall, results of this study should help to monitor the trends of detrimental variations in public building projects. Remarkably, one of the main contributions of this study lies in the fact that, it was able to identify set of mitigation measures of detrimental variations in public building projects in Tanzania. Another significant contribution of this study is that, it sheds light and provides insights on the understanding of the way forward in mitigating detrimental variations in public building projects. It also expands the efforts of studying and evaluating the potential mitigation measures of detrimental variations across the world and particularly in developing countries. Furthermore, one notable contribution of this study is that, it extends and builds upon previous researchers' works such as Hao et al. [14] who acknowledged that there is a very limited research work addressing the change management issues specifically within the construction project management context. Hence, this study makes a contribution to fill that lacunae and heed Hao et al. [14] plea for pioneers to carry extensive research on mitigation measures of detrimental variations in building projects. 


\section{Acknowledgements}

The authors wish to gratefully acknowledge, with thanks, the Arusha Technical College (ATC) of Tanzania and Makerere University (MAK) of Kampala Uganda for providing the required necessary resources that made this research possible. The authors are thankful to agencies, institutions, the consultants, the contractors and individuals for providing data needed for the study.

\section{References}

[1] Y. B. Mhando, R. S. Mlinga, and H. M Alinaitwe, Factors Influencing Variations in Public Building Projects, In: Emuze, F. A. (ed.). Proceedings of the Fourth Construction Management Conference, $30^{\text {th }}$ November- $1^{\text {st }}$ December, Protea Marine Hotel, Port Elizabeth, South Africa, NMMU, 2015, 162-170.

[2] E. E. Rwakarehe and D. A. Mfinanga, Effect of Inadequate Design on Cost and Time Overrun of Road Construction Projects in Tanzania, Journal of Construction Engineering and Project Management, 4(1), 2014, 15-28.

[3] Y. B. Mhando, R. S. Mlinga, and H. M. Alinaitwe, Perspectives of the Causes of Variations in Public Building Projects in Tanzania, International Journal of Construction Engineering and Management, 6(1), 2017, 1-12.

[4] R. S. Mlinga, Ethics in Public Procurement: A Missing Link in the Education and Training of Construction Industry Practitioners, Proceedings of Construction Industry Forum, September12-13, Dar es Salaam, Tanzania, 2008, 1-19.

[5] T. Subramani, P. S. Sruthi, and M. Kavitha, Causes of Cost Overrun in Construction, Journal of Engineering, 4(6), $2014,1-7$.

[6] E. Ubani, C. Nwachukwu, and O. Nwokonkwo, Variation Factors of Project Plans and their Contributions to Project Failure in Nigeria, American Journal of Social and Management Sciences, 1(2), 2010, 141-149.

[7] F. M. Arain and L. S. Pheng, A Knowledge-Based System as a Decision Making Tool for Effective Management of Variations and Design Improvement: Leveraging on Information Technology Applications, ITcon, 11 (2006), 2006, 373-392.

[8] A. H. Memon, I. A. Rahman, and M. F. A. Hasan, Significant Causes and Effects of Variation Orders in Construction Projects, Research Journal of Applied Sciences, Engineering and Technology, 7(21), 2014, 4494-4502.

[9] F. M. Arain, Strategic Management of Variation Orders for Institutional Buildings: Leveraging on Information Technology, Paper Presented at the PMI Global Congress Proceedings, Toronto, PMI, 2005, 1-17.

[10] A. G. Moghaddam, Change Management and Change Process Model for the Iranian Construction Industry, International Journal of Management Business Research, 2(2), 2012, 85- 94.

[11] T. H. S. Priyantha, G. Karunasena, and V. A. K. Rodrigo, Causes, Nature and Effects of Variations in Highways, Journal of Built Environment Sri Lanka, 09 - 10(01 - 02), 2011, 14-20.

[12] Entrusty Group, What Constitute Variations and How to Evaluate Them? Master Builders Journal, 4, $2008,82-92$.

[13] S. S. Nachatar, A. A. Hussin, and A. Omran, Variations in Government Contract in Malaysia, Journal of Information Management, 2, 2010, 40-53.

[14] Q. Hao, W. Shen, J. Neelamkavil, and R. Thomas, Change Management in Construction Projects, CIB W78 International Conference on Information Technology in Construction, Santiago, Chile, 2008.

[15] S. O. Babatunde, Quantitative Assessment of Cost and Time Implication of Susceptibility of Building Elements to Variation in Nigeria, International Journal of Sustainable Construction Engineering and Technology, 4(2), 2013, 93-103.

[16] A. Ismail, T. Pourrostam, A. Soleymanzadeh, and M. Ghouyounchizad, Factors Causing Variation Orders and their Effects in Roadway Construction Projects, Research Journal of Applied Sciences, Engineering and Technology, 4(23), $2012,4969-4972$.

[17] D. Megha and B. Rajiv, A Methodology for Ranking of Causes of Delay for Residential Construction Projects in Indian Context, International Journal of Emerging Technology and Advanced Engineering, 3(3), 2013, 396-404.

[18] Y. Park and T. C. Papadopoulou, Causes of Cost Overruns in Transport Infrastructure Projects in Asia, Built Environment Project and Asset Management, 2(2), 2012, 195-216.

[19] A. O. Aiyetan and J. J. Smallwood, Professionals' Perceptions Regarding Factors Influencing Project Delivery Time, Proceedings TG59 People in Construction, 12-14 July, Port Elizabeth, South Africa, 2009, 225-234.

[20] S. Rajeev and P. S. Kothai, Study on the influence of stakeholders in construction projects, Journal of Construction Engineering and Project Management, 4(2), 2014, 8-11.

[21] F. A. Emuze and J. J. Smallwood, Improving Project Delivery in South African Construction. In: Egbu, C. and Lou, E. C. W (eds), Proceedings 27 ${ }^{\text {th }}$ Annual ARCOM Conference, 5-7 September 2011, Bristol, UK, Association of Researchers in Construction Management, , 2011, 921-930.

[22] M. Tadayon, M. Jaafar, and E. Nasri, An Assessment of Risk Identification in Large Construction Projects in Iran, Journal of Construction in Developing Countries, 1, 2012, 57-69.

[23] M. A. Ammar, A. A. Elsamdomy, and A. A. Rabie, Risk Allocation and Mitigation in the Egyptian Barrage Projects, Proceedings of the $13^{\text {th }}$ International Conference on Structural and Geotechnical Engineering, 27-29 December, Cairo-Egypt, Ain Shams University, 2009, 180-190.

[24] A. Enshasi, S. Mohamed, and S. Abushaban, Factors affecting the Performance of Construction Projects in the Gaza Strip, Journal of Civil Engineering and Management, 15(3), 2009, 269-280.

[25] R. Mohemad, A. R. Hamdan, Z. A. Othman, and N. M. M. Noor, Decision Support Systems in Construction Tendering Process, Internal Journal of Computer Science Issues, 7(2), 2010, 35-45.

[26] H. M. Alinaitwe, K. Widén, J. Mwakali, and B. Hansson, Innovation Barriers and Enablers that Affect Productivity in Uganda Building Industry, Journal of Construction in Developing Countries, 12(1), 2007, 59-75.

[27] R. K. Yin, Case study research: design and methods (4th ed. London: SAGE Publications, 2009).

[28] R. Fellows and A. Liu, Research methods for construction (3rd ed. United Kingdom: Blackwell Publishing Ltd, 2008).

[29] D. K. Kombo and D. L. A. Tromp, Proposals and thesis writing: an introduction (Nairobi: Pauline's Publications Africa, 2006)

[30] T. Palys, Purposive Sampling, In L. M. Given (ed.). The Sage Encyclopedia of Qualitative Research Methods, Los Angeles: Sage, 2, 2008, 697-698.

[31] L. A. Palinkas, S. M. Horwitz, C. A. Green, J. P. Wisdom, N. Duan, and K. Hoagwood, Purposeful Sampling for Qualitative Data Collection and Analysis in Mixed Method Implementation Research, Adm Policy Ment Health, 42(5), 2015, 533-44.

[32] D. C. Tongco, Purposive Sampling as a Tool for Informant Selection, Journal of Plants, People \& Applied Research, 5, 2007, 147158.

[33] H. M. Alinaitwe and, R. Ayesiga, Success Factors for the Implementation of Public-Private Partnerships in the Construction Industry in Uganda, Journal of Construction in Developing Countries, 18(2), 2013, 1-14. 
[34] I. Mahamid and N. Dmaidi, Risks Leading to Cost Overrun in Building Construction from Consultants' Perspectives, International Journal of Organisation, Technology and Management in Construction, 5(2), 2013, 860-873.

[35] H. Alinaitwe, W. Nyamutale, and D. Tindiwensi, Design Phase Constructability Improvement Strategies for Highway Projects in Uganda, Journal of Construction in Developing Countries, 19(1), 2014, 127-140.

[36] M. T. Zadeh, R. Dehghan, J. Y. Ruwanpura, and G. Jergeas, Factors Influencing Design Changes in Oil and Gas Projects, International Journal of Construction Engineering and Management, 3(4), 2014, 117-133.

[37] E. O. Aiyewalehinmi, Factor Analysis of Job Motivation in the Construction Industry, Research Inventory, International Journal of Engineering and Science, 3(7), 2013, 34-42.

[38] D. W. M. Chan and H. T. W. Hung, An empirical survey of the perceived benefits of implementing the mandatory building inspection scheme (MBIS) in Hong Kong, Facilities Journal, 33(5/6), 2015, 337-366. 